\title{
Analisa Tingkat Resiko Pada Komponen Pembangkit Listrik di Kota Balikpapan Menggunakan Metode FMEA
}

\author{
Faisal Manta $^{{ }^{*}}$, Hadhimas Dwi Haryono ${ }^{2}$, Risdianto Ardani ${ }^{3}$, \\ ${ }^{1}$ Staf Pengajar Teknik Mesin Institut Teknologi Kalimantan, Balikpapan, Indonesia \\ ${ }^{2}$ Staf Pengajar Teknik Mesin Institut Teknologi Kalimantan, Balikpapan, Indonesia \\ ${ }^{3}$ Mahasiswa Teknik Mesin Institut Teknologi Kalimantan, Balikpapan, Indonesia \\ *Email :faisal86@itk.ac.id
}

\begin{abstract}
Company $X$ is a power plant that supplies Balikpapan city electricity. In order to maintain the availability of electricity, regular maintenance is carried out, predictive, preventive and corrective maintenance in company X. The maintenance scheme of each component is based on the level of risk and priority scale. In this study, the determination of the level of risk and priority scale for each component uses Failure Mode And Effect Analysis (FMEA). The subject of the research was the W2OV320 engine type diesel fuel component in the X power plant in Balikpapan City. Maintenance data for 2 years, 2017 and 2018, with 420 failure modes from 67 components used as research data. Engines are grouped into 12 systems and each system has a RPN (Risk Priority Number) value. In the $R P N$ the Severity, Occurance, and Detection values are arranged based on company X's condition at the time the report is written. The highest RPN value is found in the Radiator Motor Fan component in the Radiator system and the LO Separator component in the Lube Oil Supply System which is 144. Components with an RPN value> 40 receive predictive and preventive maintenance services, while components with an RPN value <20 get corrective maentenance services.
\end{abstract}

Keywords : FMEA Maintenance, RPN

\begin{abstract}
Abstrak
Perusahaan X merupakan pembangkit yang memasok listrik kota Balikpapan. Perawatan berkala dilakukan demi menjaga ketersedian listrik yaitu predictive, preventive dan corrective maintenance. Skema perawatan setiap komponen berdasarkan tingkat resiko dan skala prioritas. Pada penelitian dilakukan penentuan tingkat resiko dan skala prioritas setiap komponen menggunakan Failure Mode And Effect Analysis (FMEA). Subjek penelitian adalah komponen Engine tipe W20V320 berbahan bakar marine fuel oildi perusahaan X. Data perawatan di tahun 2017 dan 2018, 67 komponen dan 420 mode kegagalan sebagai bahan penelitian. Engine diklasifikasi menjadi 12 sistem dan setiap sistem memiliki nilai RPN (Risk Priority Number). Nilai Severity, Occurance, dan Detection pada RPN disusun berdasarkan kondisi perusahaan X disaat laporan ditulis. Nilai RPNtertinggi terdapat pada komponen Radiator Motor Fan di sistem Radiator dan Komponen LO Separator di sistem Lube Oil Supply System yaitu 144. Komponen dengan nilai RPN lebih dari 40 mendapatkan jenis perawatan predictive dan preventive, sedangkan komponen dengan nilai RPN kurang dari 20 mendapatkan perawatan corrective.
\end{abstract}

Kata kunci : FMEA, Maintenance, RPN

\section{Pendahuluan}

\subsection{Latar Belakang}

Listrik telah menjadi kebutuhan pokok yang wajib terpenuhi ketersediannya, tidak terkecuali Kota Balikpapan Kalimantan Timur. Kota Balikpapan memiliki luas wilayah 503,3 $\mathrm{km}^{2}$ berpeduduk 645.727 jiwa dengan konsumsi listrik mencapai 652.363 kW/bulan[1]. Listrik Kota Balikpapan didukung oleh beberapa pembangkit yang menyebar di sekitar Kaltim.

Perusahaan $\mathrm{X}$ merupakan pembangkit swasta yang menyediakan listik Kota Balikpapan dengan daya 45 MW. 5 unit engine berbahan bakar marine fuel oil digunakan sebagai pembangkit utama. Perusahaan X telah melakukan pengembangan sejak berdirinya di tahun 2009. Perawatan secara berkala 
dilakukan dengan predictive, preventive dan corrective maintenance[2][3].

Perusahaan $\mathrm{X}$ telah berkomitmen untuk tetap melakukan pengembangan secara berkelanjutan, demi memenuhi kebutuhan listrik Kota Balikapapan yang terus meningkat. Memaksimalkan potensi sumber daya dengan menganalisa kegagalan yang telah terjadi dan fokus pada akar permasalahan.

Metode FMEA membantu perusahaan mengembangkan analisa resiko dalam manajemen pemeliharaan [4]. Metode yang sistematis, terorganisasi dan efisieni, sehinggaperusahaan mampu menyusun rencana menghadapi kondisi kritis untuk meningkatkan keandalan [5]. Potensi kegagalan diminimalisir atau dihilangkan hingga ke akar permasalahan, untuk mencegah kegagalan terulang kembali dikemudian hari.

Permasalahan penelitian dapat dirumuskan berdasarkan latar belakang yang telah dijabarkan yaitu;

- Evaluasi dan klasifikasi mode kegagalan sistem pada perusahaan.

- Indentifikasi tingkat resiko untuk setiap mode kegagalan dan akar permasalahan dengan FMEA.

- Menentukan tingkat kritis berdasarkan perhitungan FMEA.

Pada tahap awal, setiap potensi kegagalan dikualifikasikan berdasarkan skala prioritas penanganan. Skala prioritas disusun menurut kondisi resiko efek kegagalan terhadap operasional sistem dan proses di perusahaan. Parameter yang digunakan dalam penyusunan skala prioritas adalah tingkat kerusakan (severity), frekuensi kerusakan (occurance) dan tingkat deteksi (detection). Severity merupakan luasan efek kegagalan terhadap operasional proses dan produksi. Occurance adalah kerap jumlah terjadinya kegagalan dalam satuan kerja periode tertentu. Detection merupakan kemampuan untuk membaca indikasi-indikasi kegagalan. Kemampuan indikasi dapat dipengaruhi oleh kapabel karyawan dan kelengkapan alat pendukung, sehingga tingkat deteksi semakin tinggi[6 ].

FMEA memiliki fleksibilitas prosedur karena tujuan organisasi, proses, produk dan pelanggan yang berbeda setiap perusahaan. Keuntungan bagi perusahaan, jika FMEA dilakukan dengan baik antara lain meminimalisir kegagalan terulang kembali, mengurangi kerugian akibat kegagalan, mengurangi kejadian tidak terduga, peningkatan proses, kualitas/kuantitas produk, keandalan dan keselamatan, orientasi pada hasil, fokus atas tindakan pencegahan [7].

\section{Metode Penelitian}

Metode penelitian dimulai dari klasifikasi mode kegagalan, indentifikasi tingkat resiko dan perhitungan resiko[8].

\subsection{Klasifikasi Mode Kegagalan}

Klasifikasi mode kegagalan terhadap data kerusakan komponen selama tahun 2017 dan 2018. Data diklasifikasikan menurut sistem kerja enggine dan setiap sistem berisi semua mode kegagalan dari komponen yang terlibat. Mode kegagalan disusun berdasarkan penyebab dan dampak yang terjadi. Penyebab dijabarkan hingga permasalahan paling mendasar untuk ditemukan akar masalahnya. Dampak dijabarkan hingga efek atau potensi terbesar yang mungkin terjadi.

\subsection{Indentifikasi Tingkat Resiko}

Pada tahap berikutnya dilakukan analisa tingkat kerusakan, frekuensi, dan deteksi dari semua mode kegagalan. Keseluruhan data kerusakan, frekuensi, dan deteksi diubah ke dalam bentuk nilai skala satuan ordinal dari 1 sampai 10.Skala ditentukan menurut data primer dari objek yang diteliti seperti checksheet inspeksi harian dan wawancara dengan tenaga ahli. Skala tersebut digunakan untuk perhitungan RPN (Risk Priority Number). 


\subsection{Perhitungan Resiko}

Pada tahap akhir dilakukan perhitungan nilai RPN (Risk Priority Number). Rumusan adalah sebagai berikut [9]:

$$
\mathrm{RPN}=\mathrm{S} \times \mathrm{O} \times \mathrm{D} \ldots \ldots \ldots \ldots
$$

$\mathrm{S}$ : Nilai Saverity

$\mathrm{O}$ : Nilai Occurance

D : Nilai Detection

Hasil analisa nilai RPN menjadi dasar penyusunan tingkat prioritas penanggulangan mode kegagalan.

\section{Hasil Penelitian}

\subsection{Hasil Klasifikasi Mode Kegagalan}

Berdasarkan data kegagalan komponen tahun 2017 dan 2018, diperoleh bahwa engine tipe W20V320 mengalami 420 mode kegagalan. Mode kegagalan diklasifikasikan dalam 12 sistem dengan 55 komponen dan efek kegagalan untuk setiap komponen seperti yang ditunjukkan pada tabel 1 [10] (disajikan pada lampiran).

Pada sistem enginememiliki 8 komponen yaitu engine, cylinder head, starting valve, pushrod inlet, flywheel connection, camshaft, cranksaft, crankcase pressure dengan mode kegagalan adalah kegagalan fungsi, kebocoran, keausan dan kesalahan perakitan. Dampak yang terjadi adalah turunnya performansi enggine hingga terhentinya operasi.

Pada sistemturbocharger terdiri dari 7 komponen yaitu turbocharger, gas inlet chasing, nozzle ring, turbocharger washing unit, speed measurement, compressor unit (Starting Air Equipment), instrument air Equipment dengan mode kegagalan yaitu kegagalan fungsi, keberadaan pengotor dan keausan. Dampak yang dimiliki adalah penurunan performasi hingga berhentinya operasi.

Pada water cooling systemmemiliki 5 komponen yaitu HT/LT water looling system, heat exchange, charge air cooler, HT water treeway valve, HT preheater dengan mode kegagalan adalah keberadaan pengotor, kebocoran, kegagalan fungsi. Efek yang terjadi adalah penurunan kapasitas listrik hingga operasi terhenti.
Pada sistem radiator memiliki 4 komponen yaitu freq. konverter, section radiator, radiator motor fan, radiator panel control dengan mode kegagalan adalah keberadaan pengotor, kegagalan fungsi, kebocoran, kesalahan perawatan. Dampak yang terjadi adalah penurunan kapasitas listrik hingga operasi terhenti.

Pada sistem booster modul memiliki 6 komponen yaitu booster modul, booster pump, pressure indicator, temperature indicator, $\mathrm{FO}$ duflex filter, mixing tank dengan mode kegagalan kebocoran, kegagalan fungsi alat, keberadaan pengotor. Efek yang tejadi adalah penurunan pasokan listrik hingga operasi terhenti.

Pada sistemfuel injection system memiliki 4 komponen yaitu fuel injection system, fuel pump cylinder, charge air filter, pressure indicator dengan mode kegagalan adalah kebocoran, kegagalan fungsi, keberadaan pengotor. Dampak yang terjadi adalah penurunan pasokan listrik hingga terhentinya operasi.

Pada sistem exhaust gas system memiliki 5 komponen yaitu exhaust gas system, exhaust manifold, double bellows, exhaust stack, pneumatic control dumper dengan mode kegagalan kerusakan sambungan, korosi, kebocoran. Efek yang terjadi adalah pencemaran lingkungan.

Pada sistem lube oil supply system memiliki 6 komponen yaitu lube oil supply system, lube oil cooler, LO automatic filter, LO centrifugal filter, oil mist separator, LO separator dengan mode kegagalan yaitu kebocoran, keberadaan pengotor, kegagalan fungsi. Efek yang terjadi kelebihan panas hingga menghentikan operasi.

Pada sistem governormemiliki 1 komponen yaitu governor dengan mode kegagalan pengaturan timing, kesalahan instalisasi, kegagalan fungsi. Efek yang terjadi adalah penurunan performansi hingga operasi terhenti.

Pada sistem generatormemiliki 1 komponen yaitu generator setdengan mode kegagalan starting, kesalahan instalisasi, 
kegagalan fungsi. Efek yang terjadi adalah operasi terhenti.

Pada sistem bearing memiliki 2 komponen yaitu bearing set, bearing generator dengan mode kegagalan adalah kerusakan fisik, kesalahan instalisasi, kebocaran, keausan. Efek yang terjadi adalah panas, suara dan getaran tinggi, penurusan pasokan listrik hingga terhentinya operasi.

Pada sistem local controlmemiliki 6 komponen yaitu pressure measurement, speed measurement, temperature measurement, engine safety modul, power distribution modul, pneumatic control dengan mode kegagalan kegagalan fungsi pengukuran. Efek yang terjadi adalah penurunan kapasitas listrik hingga terhentinya operasi.

\subsection{Hasil Indentifikasi Resiko}

Hasil analisa setiap mode kegagalan berdasarkan tingkat kerusakan (severity), frekuensi (occurance), dan deteksi (detection) disajikan dalam bentuk tabel skala ordinal. Tabel skala ordinal dengan parameter skala, kriteria dan efek produksi. Skala adalah tingkat/level parameter yang diukur.Kriteria merupakan definisi skala atau kejadian di lapangan pada tingkat tersebut. Efek adalah kejadian terhadap sistem produksi pada tingkat skala tersebut dalam satuan (unit, jam produksi/proses).

\section{A. Severity}

Severity merupakan nilai tingkat keparahan yang ditimbulkan akibat mode kegagalan sebuah komponen. Penilaian berdasarkan fungsi dan peranan komponen tersebut pada proses produksi, semakin vital maka semakin tinggi nilai komponen tersebut. Nilai pada severitydinyatakan dengan nominal angka 1 sampai 10, dimulai dari yang memiliki dampak paling ringan hingga yang terberat seperti pada tabel 2 Nilai severity [10].
Tabel 2 Nilai $\underline{\text { Severity }}$

\begin{tabular}{|c|c|c|c|}
\hline $\mathrm{NO}$ & Skala & Kriteria & Efek \\
\hline 1 & $\begin{array}{l}\text { Tidak } \\
\text { ada } \\
\text { Akibat }\end{array}$ & $\begin{array}{l}\text { Tidak } \\
\text { mengakibatkan } \\
\text { apa apa, tidak } \\
\text { memerlukan } \\
\text { penyesuaian. }\end{array}$ & $\begin{array}{l}\text { Proses berada } \\
\text { dalam kendali } \\
\text { tanpa } \\
\text { melakukan } \\
\text { penyesuaian } \\
\text { peralatan. }\end{array}$ \\
\hline 2 & $\begin{array}{l}\text { Akibat } \\
\text { sangat } \\
\text { Ringan }\end{array}$ & $\begin{array}{l}\text { Mesin tetap } \\
\text { beroperasi dengan } \\
\text { aman, hanya } \\
\text { terjadi sedikit } \\
\text { gangguan } \\
\text { peralatan yang } \\
\text { tidak berarti. } \\
\text { Akibat hanya } \\
\text { diketahui oleh } \\
\text { operator } \\
\text { berpengalaman. }\end{array}$ & $\begin{array}{l}\text { Proses dalam } \\
\text { pengendalian, } \\
\text { hanya } \\
\text { membutuhkan } \\
\text { sedikit } \\
\text { penyesuaian. }\end{array}$ \\
\hline 3 & $\begin{array}{l}\text { Akibat } \\
\text { Ringan }\end{array}$ & $\begin{array}{l}\text { Mesin tetap } \\
\text { beroperasi dengan } \\
\text { aman, hanya ada } \\
\text { sedikit gangguan. } \\
\text { Akibat diketahui } \\
\text { oleh rata rata } \\
\text { operator. }\end{array}$ & $\begin{array}{l}\text { Proses telah } \\
\text { berada diluar } \\
\text { kendali, } \\
\text { beberapa } \\
\text { penyesuaian } \\
\text { diperlukan. }\end{array}$ \\
\hline 4 & $\begin{array}{l}\text { Akibat } \\
\text { Minor }\end{array}$ & $\begin{array}{l}\text { Mesin tetap } \\
\text { beroperasi dengan } \\
\text { aman, nemun } \\
\text { terdapat gangguan } \\
\text { kecil. Akibat } \\
\text { diketahui oleh } \\
\text { semua operator. }\end{array}$ & $\begin{array}{l}\text { Kurang dari } \\
30 \text { menit } \\
\text { Downtime } \\
\text { atau tidak ada } \\
\text { Downtime } \\
\text { sama sekali. }\end{array}$ \\
\hline 5 & $\begin{array}{l}\text { Akibat } \\
\text { Modera } \\
\mathrm{t}\end{array}$ & $\begin{array}{l}\text { Mesin tetap } \\
\text { beroperasi } \\
\text { normal, namun } \\
\text { telah } \\
\text { mengakibatkan } \\
\text { beberapa } \\
\text { kegagalan produk. } \\
\text { Operator merasa } \\
\text { tidak puas karena } \\
\text { tingkat kinerja } \\
\text { berkurang. } \\
\end{array}$ & $\begin{array}{l}30 \text { sampai } 60 \\
\text { menit } \\
\text { Downtime }\end{array}$ \\
\hline 6 & $\begin{array}{l}\text { Akibat } \\
\text { Signifi } \\
\text { kan }\end{array}$ & $\begin{array}{l}\text { Mesin tetap } \\
\text { beroperasi dengan } \\
\text { aman, tetapi } \\
\text { menimbulkan } \\
\text { kegagalan produk. } \\
\text { Operator merasa } \\
\text { sangat tidak puas } \\
\text { dengan kinerja } \\
\text { mesin. }\end{array}$ & $\begin{array}{l}\text { 1 sampai } 2 \\
\text { jam Downtime }\end{array}$ \\
\hline 7 & $\begin{array}{l}\text { Akibat } \\
\text { Besar }\end{array}$ & $\begin{array}{l}\text { Mesin tetap } \\
\text { bekerja dengan } \\
\text { aman, tetapi tidak }\end{array}$ & $\begin{array}{l}2 \text { sampai } 4 \\
\text { jam Downtime }\end{array}$ \\
\hline
\end{tabular}




\begin{tabular}{|c|c|c|c|}
\hline \multicolumn{4}{|c|}{ JURNAL SAINS TERAPAN VOL. 6 NO. 12020} \\
\hline & & $\begin{array}{l}\text { dapat dijalankan } \\
\text { secara penuh. } \\
\text { Operator merasa } \\
\text { sangat tidak puas. }\end{array}$ & \\
\hline 8 & $\begin{array}{l}\text { Akibat } \\
\text { Ekstre } \\
\mathrm{m}\end{array}$ & $\begin{array}{l}\text { Mesin tidak dapat } \\
\text { beroperasi dan } \\
\text { telah kehilangan } \\
\text { fungsi utamanya. }\end{array}$ & $\begin{array}{l}4 \text { sampai } 8 \\
\text { jam Downtime }\end{array}$ \\
\hline 9 & $\begin{array}{l}\text { Akibat } \\
\text { Serius }\end{array}$ & $\begin{array}{l}\text { Mesin gagal } \\
\text { beroperasi, serta } \\
\text { tidak sesuai } \\
\text { dengan peraturan } \\
\text { keselamatan } \\
\text { kerja. }\end{array}$ & $\begin{array}{l}\text { Lebih besar } \\
\text { dari } 8 \text { jam } \\
\text { Downtime }\end{array}$ \\
\hline 10 & $\begin{array}{l}\text { Akibat } \\
\text { Berbah } \\
\text { aya }\end{array}$ & $\begin{array}{l}\text { Mesin tidak layak } \\
\text { di operasikan, } \\
\text { karena dapat } \\
\text { menimbulkan } \\
\text { kecelakaan secara } \\
\text { tiba tiba, dan } \\
\text { bertentangan } \\
\text { degan peraturan } \\
\text { keselamatan. }\end{array}$ & $\begin{array}{l}\text { Lebih besar } \\
\text { dari } 8 \text { jam } \\
\text { Downtime }\end{array}$ \\
\hline
\end{tabular}

B. Occurance

Occurancemerupakan nilai tingkat frekuensi munculnyamode kegagalan pada komponen tersebut. Occurance berhubungan dengan panjangnya waktu operasi komponen sebelum mode kegagalan terjadi kembali, semakin panjang waktu operasi komponen, maka semakin kecil nilai skala occurance. Nilai pada skala occurance yaitu antara 1 sampai 10, dimana nilai diberikan untukmode kegagalan dengan intensitas rendahhinggatinggi seperti pada tabel 3 nilai occurance [10].

Tabel 3 Nilai Occurance

\begin{tabular}{|c|c|c|c|}
\hline $\mathrm{NO}$ & Skala & Kriteria & Efek \\
\hline 1 & $\begin{array}{l}\text { Hampir } \\
\text { Tidak } \\
\text { Pernah }\end{array}$ & $\begin{array}{l}\text { Kerusakan } \\
\text { hampir tidak } \\
\text { pernah terjadi. }\end{array}$ & $\begin{array}{l}\text { Lebih dari } \\
10.000 \text { jam } \\
\text { operasi mesin. }\end{array}$ \\
\hline 2 & Jarang & $\begin{array}{l}\text { Kerusakan } \\
\text { jarang terjadi. }\end{array}$ & $\begin{array}{l}6001 \text { sampai } \\
10.000 \text { jam } \\
\text { operasi mesin } \\
\end{array}$ \\
\hline 3 & $\begin{array}{l}\text { Sangat } \\
\text { Sedikit }\end{array}$ & $\begin{array}{l}\text { Kerusakan yang } \\
\text { terjadi sangat } \\
\text { sedikit. }\end{array}$ & $\begin{array}{l}3001 \text { sampai } \\
6000 \text { jam } \\
\text { operasi mesin. }\end{array}$ \\
\hline 4 & Sedikit & $\begin{array}{l}\text { Kerusakan yang } \\
\text { terjadi sedikit. }\end{array}$ & $\begin{array}{l}2001 \text { sampai } \\
3000 \text { jam } \\
\text { operasi mesin. }\end{array}$ \\
\hline 5 & Rendah & $\begin{array}{l}\text { Kerusakan yang } \\
\text { terjadi pada } \\
\text { tingkat rendah. }\end{array}$ & $\begin{array}{l}1001 \text { sampai } \\
2000 \text { jam } \\
\text { operasi mesin. }\end{array}$ \\
\hline
\end{tabular}

e-ISSN 2477-5525

p-ISSN 2406-8810

\begin{tabular}{|c|c|c|c|}
\hline 6 & Medium & $\begin{array}{l}\text { Kerusakan yang } \\
\text { terjadi pada } \\
\text { tingkat medium. }\end{array}$ & $\begin{array}{l}401 \text { sampai } \\
1000 \text { jam } \\
\text { operasi mesin. }\end{array}$ \\
\hline 7 & $\begin{array}{l}\text { Cukup } \\
\text { Tinggi }\end{array}$ & $\begin{array}{l}\text { Kerusakan yang } \\
\text { terjadi cukup } \\
\text { tinggi. }\end{array}$ & $\begin{array}{l}101 \text { sampai } \\
400 \text { jam } \\
\text { operasi mesin. }\end{array}$ \\
\hline 8 & Tinggi & $\begin{array}{l}\text { Kerusakan yang } \\
\text { terjadi tinggi. }\end{array}$ & $\begin{array}{l}11 \text { sampai } 100 \\
\text { jam operasi } \\
\text { mesin. }\end{array}$ \\
\hline 9 & $\begin{array}{l}\text { Sangat } \\
\text { tinggi }\end{array}$ & $\begin{array}{l}\text { Kerusakan yang } \\
\text { terjadi sangat } \\
\text { tinggi. }\end{array}$ & $\begin{array}{l}2 \text { sampai } 10 \\
\text { mesin operasi } \\
\text { mesin. }\end{array}$ \\
\hline 10 & $\begin{array}{l}\text { Hampir } \\
\text { Setiap } \\
\text { Saat }\end{array}$ & $\begin{array}{l}\text { Hampir setiap } \\
\text { saat terjadi. }\end{array}$ & $\begin{array}{l}\text { Kurang dari } 2 \\
\text { jam operasi } \\
\text { mesin. }\end{array}$ \\
\hline
\end{tabular}

\section{Detection}

Detectionmerupaan skala nilai deteksi awal terhadap indikasi dan gejala mode kegagalan sebelum terjadi. Penilaian dipengaruhi oleh ketersediaan alat ukur sebagai sarana untuk deteksi dini dan kemampuan teknisi. Semakin akurat deteksi yang dapat dilakukan, maka semakin kecil nilai skala detection. Skala nilai detectiondinyatakan seperti pada tabel dengan nilai 1 hingga 10, mulai dari terdeteksi akurat hingga yang sulit dideteksi seperti pada tabel 4 nilai detection [10].

Tabel 4 Nilai detection

\begin{tabular}{|c|c|c|}
\hline No & Akibat & Kriteria Verbal \\
\hline 1 & $\begin{array}{l}\text { Hampir Selalu } \\
\text { Terjadi }\end{array}$ & $\begin{array}{l}\text { Kontrol selalu dapat } \\
\text { mendeteksi } \\
\text { penyebab potensial } \\
\text { atau mekanisme } \\
\text { kegagalan dan mode } \\
\text { kegagalan. }\end{array}$ \\
\hline 2 & Sangat Tinggi & $\begin{array}{l}\text { Kontrol memiliki } \\
\text { kemungkinan sangat } \\
\text { tinggi untuk } \\
\text { mendeteksi } \\
\text { penyebab potensial } \\
\text { atau mekanisme } \\
\text { kegagalan dan mode } \\
\text { kegagalan. }\end{array}$ \\
\hline 3 & Tinggi & $\begin{array}{l}\text { Kontrol memiliki } \\
\text { kemungkinan tinggi } \\
\text { untuk mendeteksi } \\
\text { penyebab potensial } \\
\text { atau mekanisme } \\
\text { kegagalan dan mode } \\
\text { kegagalan. }\end{array}$ \\
\hline 4 & Cukup Tinggi & $\begin{array}{l}\text { Kontrol memiliki } \\
\text { kemungkinan } \\
\text { "Moderately High", }\end{array}$ \\
\hline
\end{tabular}




\begin{tabular}{|c|c|c|}
\hline \multicolumn{3}{|c|}{ JURNAL SAINS TERAPAN VOL. 6 NO. 12020} \\
\hline & & $\begin{array}{l}\text { untuk mendeteksi } \\
\text { penyebab potensial } \\
\text { atau mekanisme } \\
\text { kegagalan dan mode } \\
\text { kegagalan. }\end{array}$ \\
\hline 5 & Cukup & $\begin{array}{l}\text { Kontrol memiliki } \\
\text { kemungkinan } \\
\text { "Moderate" untuk } \\
\text { mendeteksi } \\
\text { penyebab potensial } \\
\text { atau mekanisme } \\
\text { kegagalan dan mode } \\
\text { kegagalan. }\end{array}$ \\
\hline 6 & Rendah & $\begin{array}{l}\text { Kontrol memiliki } \\
\text { kemungkinan rendah } \\
\text { untuk medeteksi } \\
\text { penyebab potensial } \\
\text { atau mekanisme } \\
\text { kegagalan dan mode } \\
\text { kagagalan. }\end{array}$ \\
\hline 7 & Sangat Rendah & $\begin{array}{l}\text { Kontrol memiliki } \\
\text { kemungkinan sangat } \\
\text { rendah untuk } \\
\text { mendeteksi } \\
\text { penyebab potensial } \\
\text { atau mekanisme } \\
\text { kegagalan dan mode } \\
\text { kegagalan. }\end{array}$ \\
\hline 8 & Remote & $\begin{array}{l}\text { Kontrol memiliki } \\
\text { kemungkinan } \\
\text { remote untuk } \\
\text { mendeteksi } \\
\text { penyebab potensial } \\
\text { atau mekanisme } \\
\text { kegagalan dan mode } \\
\text { kegagalan. }\end{array}$ \\
\hline 9 & Very Remote & $\begin{array}{l}\text { Kontrol memiliki } \\
\text { kemungkinan Very } \\
\text { Remote untuk } \\
\text { mendeteksi } \\
\text { penyebab kegagalan } \\
\text { atau mekanisme } \\
\text { kegagalan dan mode } \\
\text { kegagalan. }\end{array}$ \\
\hline 10 & Tidak pasti & $\begin{array}{l}\text { Kontrol selalu tidak } \\
\text { dapat mendeteksi } \\
\text { penyebab potensial } \\
\text { atau mekanisme } \\
\text { kegagalan dan mode } \\
\text { kegagalan. }\end{array}$ \\
\hline
\end{tabular}

\subsection{Hasil Perhitungan RPN}

Nilai RPN merupakan tingkat resiko dari mode kegagalan masing-masing komponen. Tingkat resiko menjadi skala prioritas tindakan pencegahan. Bentuk

tindakan pencegahan adalah perawatan secara berkala yaitu preventive, predictive dan corrective maintenance. Nilai RPN akan menentukan jenis perawatan berkala yang dikenakan untuk setiap komponen. Nilai RPN didapatkan dari perkalian severtiy, occurance dan detection sesuai tabel 5 nilai RPN.

\section{Tabel 5 Nilai RPN}

\begin{tabular}{|c|c|c|c|c|c|}
\hline \multirow{2}{*}{ No } & \multirow{2}{*}{ Nama Item } & \multicolumn{4}{|c|}{ Tingkat Resiko } \\
\hline & & $\mathrm{S}$ & $\mathrm{O}$ & $\mathrm{D}$ & RPN \\
\hline A & \multicolumn{5}{|c|}{ Enggine } \\
\hline 1 & Enggine & 10 & 7 & 2 & 140 \\
\hline 2 & Cylinder Head & 8 & 5 & 3 & 120 \\
\hline 3 & Starting Valve & 8 & 5 & 3 & 120 \\
\hline 4 & Pushrod Inlet & 8 & 2 & 6 & 96 \\
\hline 5 & Flywheel Connection & 6 & 2 & 6 & 72 \\
\hline 6 & Camshaft & 8 & 1 & 3 & 24 \\
\hline 7 & Crankshaft & 8 & 1 & 3 & 24 \\
\hline 8 & Crankcase Pressure & 7 & 1 & 5 & 35 \\
\hline $\mathrm{B}$ & \multicolumn{5}{|c|}{ Turbocharger } \\
\hline 1 & Turbocharger Sistem & 8 & 3 & 3 & 72 \\
\hline 2 & Gas Inlet Chasing & 3 & 1 & 6 & 18 \\
\hline 3 & Nozzle Ring & 4 & 1 & 6 & 24 \\
\hline 4 & $\begin{array}{l}\text { Turbocharger Washing } \\
\text { Unit }\end{array}$ & 4 & 4 & 5 & 80 \\
\hline 5 & Speed Measurement & 5 & 4 & 3 & 60 \\
\hline 6 & $\begin{array}{l}\text { Compressor Unit } \\
\text { (Starting Air } \\
\text { Equipment) }\end{array}$ & 7 & 3 & 3 & 63 \\
\hline 7 & $\begin{array}{l}\text { Instrument Air } \\
\text { Equipment }\end{array}$ & 7 & 2 & 3 & 42 \\
\hline $\mathrm{C}$ & \multicolumn{5}{|c|}{ Water Cooling System } \\
\hline 1 & $\begin{array}{l}\text { HT/LT Water Cooling } \\
\text { System }\end{array}$ & 7 & 6 & 3 & 126 \\
\hline 2 & Heat Exchanger & 7 & 1 & 4 & 28 \\
\hline 3 & Charge Air Cooler & 7 & 1 & 3 & 21 \\
\hline 4 & $\begin{array}{l}\text { HT Water Treeway } \\
\text { Valve }\end{array}$ & 5 & 3 & 6 & 90 \\
\hline 5 & HT Preheater & 5 & 1 & 3 & 15 \\
\hline $\mathrm{D}$ & \multicolumn{5}{|c|}{ Radiator } \\
\hline 1 & Freq. Konverter & 4 & 4 & 3 & 48 \\
\hline 2 & Section Radiator & 7 & 3 & 3 & 63 \\
\hline 3 & Radiator Motor Fan & 6 & 6 & 4 & 144 \\
\hline 4 & Radiator Panel Kontrol & 5 & 2 & 3 & 30 \\
\hline $\mathrm{E}$ & Booster & Iodu & & & \\
\hline
\end{tabular}




\begin{tabular}{|c|c|c|c|c|c|}
\hline \multicolumn{6}{|c|}{ JURNAL SAINS TERAPAN VOL. 6 NO. 12020} \\
\hline 1 & Booster Modul & 5 & 3 & 4 & 60 \\
\hline 2 & Booster Pump & 5 & 4 & 3 & 60 \\
\hline 3 & Pressure Indicator & 6 & 1 & 4 & 24 \\
\hline 4 & Temperature Indicator & 6 & 1 & 4 & 24 \\
\hline 5 & FO Duflex Filter & 5 & 3 & 4 & 60 \\
\hline 6 & Mixing Tank & 6 & 1 & 7 & 42 \\
\hline$F$ & \multicolumn{5}{|c|}{ Fuel Injection System } \\
\hline 1 & Fuel Injection System & 8 & 5 & 3 & 120 \\
\hline 2 & Fuel Pump Cylinder & 8 & 4 & 3 & 96 \\
\hline 3 & Charge Air Filter & 5 & 2 & 4 & 40 \\
\hline 4 & Pressure Indicator & 6 & 1 & 4 & 24 \\
\hline G & \multicolumn{5}{|c|}{ Exhaust Gas System } \\
\hline 1 & Exhaust Gas system & 7 & 3 & 3 & 63 \\
\hline 2 & Exhaust Manifold & 7 & 3 & 3 & 63 \\
\hline 3 & Double Bellows & 5 & 3 & 6 & 90 \\
\hline 4 & Exhaust Stack & 7 & 3 & 3 & 63 \\
\hline 5 & $\begin{array}{l}\text { Pneumatic } \\
\text { Dumper }\end{array}$ & 6 & 2 & 4 & 48 \\
\hline $\mathrm{H}$ & \multicolumn{5}{|c|}{ Lube Oil Supply System } \\
\hline 1 & Lube Oil Supply System & 7 & 1 & 3 & 21 \\
\hline 2 & Lube Oil Cooler & 5 & 3 & 4 & 60 \\
\hline 3 & LO Automatic Filter & 5 & 1 & 6 & 30 \\
\hline 4 & LO Centrifugal Filter & 6 & 5 & 4 & 120 \\
\hline 5 & Oil Mist Separator & 5 & 3 & 6 & 90 \\
\hline 6 & LO Separator & 6 & 6 & 4 & 144 \\
\hline $\mathrm{I}$ & \multicolumn{5}{|c|}{ Governor } \\
\hline 1 & Governor & 7 & 4 & 4 & 112 \\
\hline $\mathrm{J}$ & \multicolumn{5}{|c|}{ Generator } \\
\hline 1 & Generator Set & 6 & 5 & 2 & 60 \\
\hline $\mathrm{K}$ & \multicolumn{5}{|c|}{ Bearing } \\
\hline 1 & Bearing Set & 5 & 1 & 5 & 25 \\
\hline 2 & Bearing Generator & 5 & 1 & 5 & 25 \\
\hline $\mathrm{L}$ & \multicolumn{5}{|c|}{ Local Control } \\
\hline 1 & Pressure Measurement & 6 & 5 & 3 & 90 \\
\hline 2 & Speed Measurement & 6 & 3 & 3 & 54 \\
\hline 3 & $\begin{array}{l}\text { Temperature } \\
\text { Measurement }\end{array}$ & 6 & 5 & 3 & 90 \\
\hline 4 & Engine Safety Modul & 4 & 4 & 5 & 80 \\
\hline 5 & Distribution & 7 & 1 & 3 & 21 \\
\hline 6 & Pneumatic Control & 6 & 5 & 3 & 90 \\
\hline
\end{tabular}

Pada tabel 5 diketahui nilai RPN tiap komponen. Nilai RPN tertinggi di setiap sistem adalah engine 140 , turbocharger washing unit 80, ht/lt water cooling system 126 , radiator motor fan 144, booster pump 60, booster modul 60, fo duflex filter 60, fuel injection system 120, double bellows 90, lo separator 144, governor 112, generator set 60 , bearing set 25 , bearing generator 25 , pressure measurement 90, temperature measurement 90, pneumatic control 90. Nilai RPN merupakan skala prioritas pencegahan terjadinya mode kegagalan. Komponen dengan nilai RPN lebih tinggi dari 40 memiliki efek mampu menghentikan operasi kerja dengan lama waktu perbaikkan yang berbeda. Nilai RPN diantara 40 hingga 20 memiliki dampak mampu menurukan kinerja engine. Nilai RPN kurang dari 20 tidak memiliki dampak terhadap kinerja engine.

\section{Kesimpulan}

Nilai pada tabel skala tingkat kerusakan (severity), frekuensi (occurance), dan deteksi (detection) disusun berdasarkan kondisi perusahaan $X$ di saat penulisan laporan yang dapat berubah menurut waktuberdasarkan kondisi/umur peralatan, kesiapan pekerja/operator, sistem/jenis perawatan yang diterapkan.

Dengan metode FMEA diketahui bahwa nilai RPN tertinggi terdapat pada komponen Radiator Motor Fandi sistem Radiator dan Komponen LO Separatordi sistem Lube Oil Supply Systemyaitu 144. Nilai RPN terendah pada komponen HT Preheater disistem Water Cooling Sistemyaitu 15. Komponen dengan nilai RPN lebih tinggi dari 40, mendapatkan perawatan prediktif dan preventif. Komponen dengan nilai RPN lebih rendah dari 20 mendapatkan perawatan corrective.

\section{Saran}

Saran yang diberikan setelah melakukan penelitian tugas akhir ini, yaitu:

1. Pengambilan data mode kegagalan hingga 5 tahun terakhir. 
2. Melakukan validasi nilai RPN yang telah disusun, untuk dapat diterapkan langsung sesuai dengan jenis perawatan.

\section{Daftar Pustaka}

[1] BPS Balikpapan, 16 may 2019, (http://balikpapan.go.id/read/96/wilayahadministrasi, Diakses pada 8 Agustus 2019.

[2] Hartono dan ilyas Mas'udin. (2002), "Perencanaan Perawatan Mesin Dengan Metode Markov Chain Guna Menurunkan Biaya Perawatan", universitas Muhammadiyah, skripsi, Malang.

[3] Pandi dkk. (2014), "Perancangan Preventive Maintenance Pada Mesin Corrugating Dan Mesin Flexo Di Pt. Surindo Teguh Gemilang" Universitas Katolik Widya Mandala, skripsi, Surabaya.

[4] Koning J, Jaspers R, Doornink J, Ouwehand B, Klinkhamer F, Snijders B, Sadakov S. Maintenance implications of criticalcomponents in ITER CXRS upper port plug design. FusionEngineering and Design. Vol 84, Issues 7-11, 1091-1094, June2009/

[5] Ilyas Mzaugi, Zaubie El Saufi " Proposition of a modified FMEA to improve reliability of product" Procedia CIRP 84 (2019) 10031009, Elsevier, Faculty of Sciences and Technologies, Abdelmalek Essaadi University, Tangier, 90000, Morocco

[6] Badariah. Nurlailah, Surjasa. Dandang, Trinugraha. Yuda, " Analisa Supply Chain Risk Management Berdasarkan Metode FMEA, “ Universitas Trisakti, Jurnal Teknik Industri 1411-6340

[7] Raden. Budiarto, "Manajemen Risiko Keamanan Sistem Informasi Menggunakan Metode FMEA dan ISO 27001 Pada Organisasi XYZ, " STMIK Jakarta, CESS Vol 2 No.2 Juli 2017

[8] Surya. Adiyanto, Agung. Sutrisno, Charles. Punisingon, "Penerapan Metode FMEA untuk Kuantifikasi dan Pencegahan Resiko Akibat terjadinya Lean Waste, "Universitas Sam Ratulangi, Manado, Jurnal online Poros Teknik Mesin Vol 6 No 12016

[9] Firdaus H, Tri W. (2015), "Failure Mode And Effect Analysis (Fmea) Sebagai Tindakan Pencegahan Pada Kegagalan
Pengujian" Lembaga Ilmu Pengetahuan Indonesia, Pusat Penelitian Sistem Mutu dan Teknologi Pengujian, Banten.

[10] Setiawan I. (2014), "FMEA Sebagai Alat Analisa Resiko Mode Kegagalan Pada Magnetic Force Welding Machine ME-27.1", Serpong 